\title{
From Confrontation to Cooperation on the Conservation of Global Environment*
}

\section{Yujiro Hayami}

Foundation for Advanced Studies on International Development, Tokyo

\begin{abstract}
A major confrontation has prevailed between developing and developed countries on the conservation of global commons. The latter demanded internationally uniform regulations to be applied against environmental pollution, whereas the former demanded exemption for fear of the excessive burden on their industries that such regulations might impose. Developing countries' high priority in industrial and economic development is perfectly understandable. Yet, it is questionable whether their refusal to participate in international cooperative schemes for the reduction of environmental pollution, such as those in the Kyoto Protocol to the UN Framework Convention on Climate Change in 1997, is really consistent with their development goal. This question arises first from the fact that the environmental problem tends to be more severe in developing economies today than in developed economies both now and in the past. Unless serious efforts are made to reverse this tendency, their development may be significantly hampered by environmental decay. Second, it is quite possible to design an international cooperative scheme along the direction of the Kyoto Protocol, which will promote both economic development and improvement in environmental conditions in developing economies. These two aspects are the focus of this paper.
\end{abstract}

\section{Introduction}

The critical need for international cooperation on environmental problems has been widely recognized. The influence of environmental pollution is not limited to a local area, but tends to spread widely on a national and global scale. Exhaustion of tropical rain forest in a mountain area damages not only mountain tribes in the area, but also increases the incidence of flood and drought for farmers in downstream plains, and further contributes to reduction in the global supply of oxygen. Industrialization in many developing economies, if promoted

* This paper was presented as an invited lecture at the East Asian Economic Association Convention, 5-6 November 1999, Kitakyushu City, Japan. It is an updated revision of Hayami (1997, section 7.4) for incorporation in a new edition of the book. The author acknowledges helpful comments from Masaru Kohno, Masanori Kondo, Keijiro Otsuka and Takamasa Akiyama. Yue Yaguchi provided technical assistance. 
without appropriate measures, might aggravate air and water pollution to the level of global catastrophe. In the world today, when the world has increasingly been felt to be stretched to its limits by the pressure of growing population and economic activities, no country is free from the pollution caused by other countries.

This recognition has led to a series of attempts to establish international cooperation systems for the conservation and improvement of environments, from the UN Conference on Human Environment held in 1972 in Stockholm to the 1992 UN Conference on Environment and Development (the so-called 'Earth Summit') held in Rio de Janeiro (Hashimoto, 1994). In these international forums, a major confrontation prevailed between developing and developed countries. The latter demanded internationally uniform regulations to be applied against environmental pollution, whereas the former demanded exemption for fear of the excessive burden on their industries that such regulations might impose.

This confrontation was also manifested in the protocol of the Kyoto conference for the UN Framework Convention on Climate Change, held in NovemberDecember 1997. This conference was able to achieve a major advance in the prevention of global warming through agreement among developed countries on the quota of reduction in the emission of 'greenhouse gases' such as carbon dioxide and methane. Developing countries, however, refused to accept any quantitative restrictions, which lent a significant support to the opposition within developed countries against the emission quota.

Such an attitude of developing countries is perfectly understandable, considering the high priority they give to industrial and economic development. Yet, it is questionable whether their refusal to participate in international co-operative schemes for the reduction of environmental pollution, such as those in the Kyoto conference agreement, is really consistent with their development goal. This question arises first from the fact that the environmental problem tends to be more severe in developing economies today than in developed economies both now and in the past. Unless serious efforts are made to reverse this tendency, their economic development may be significantly hampered by environmental decay. Second, it is quite possible to design an international cooperative scheme along the direction of the Kyoto Protocol, which could promote both economic development and improvement in environmental conditions in developing economies. This paper focuses on these two aspects.

Its structure is as follows. Section II describes the 'environmental Kuznets curve' and illustrates it by international comparisons. The role of poverty in environmental degradation is discussed in Section III. Policies which could reduce environmental degradation without harming developing countries are set out in Section IV. In Section V it is shown how international cooperation might bring about the implementation of these policies. 


\section{The Environmental Kuznets Curve}

The problems of environmental pollution arising from such factors as emission of noxious gas and water from factories, and piles of waste from urban households are universal, but are often more serious in developing countries. Advanced economies have reached a stage at which the weight of economic activities shifts from the industrial to the service sectors in response to economic growth, so that the consumption of energy as the basic source of pollution increases more slowly than the rate of growth in national income. Moreover, people in the high-income economies have high preference for environmental amenity relative to present consumption. Therefore, they are more prepared to accept environmental regulations at the expense of present consumption.

In contrast, in the early phase of industrialization, the share of industry in domestic income expands, resulting in increases in energy consumption faster than growth in national product. Since anti-pollution regulations are usually weak in developing economies, reflecting the high rates of future discount associated with their low income levels, increased energy consumption in the industrial sector tends to boost emissions of noxious gases and liquid pollutants.

Indeed, the tendency for both energy consumption and environmental pollution to rise relative to national income in response to growth in income per capita in the initial stage of development, and decline after a certain threshold income level, has recently been confirmed by several studies (Selden and Song, 1994; Grossman and Krueger, 1995; Dasgupta and Maler, 1995). This pattern is now commonly called the 'environmental Kuznets curve', because of its similarity to the well-known hypothesis of Simon Kuznets (1955) for inequality in income distribution to change along a curve of inverted- $U$ shape in the process of economic development.

The environmental Kuznets curves are illustrated by an international comparison in Figure 1. This figure compares the positions of twenty-five countries in commercial energy consumption per 100 dollars of GNP (upper diagram) and emission of carbon dioxide per 100 dollars of GNP (lower diagram), both in 1995, relative to the 1993-95 averages of GNP per capita converted to US dollars by market exchange rates. The curves in Figure 1 represent estimates of quadratic functions with respect to GNP per capita, as reported in Table 1, with regression (1) used for the upper diagram and regression (4) for the lower diagram. Even though the fits of quadratic equations to data are not very good, the coefficient of the linear term is positive and that of the quadratic term is negative, both statistically significant at conventional levels, supporting the inverted U-shape hypothesis with respect to energy consumption and $\mathrm{CO}_{2}$ emission.

Figure 1 reveals the tendency that former socialist economies (China, Hungary, Poland, Russia and Slovakia) diverge upward from the quadratic curves. Regressions (2) and (5) include a dummy variable representing former socialist economies, which turns out to be positive and highly significant. Low energy efficiency in ex-socialist economies indicated by such statistical analysis seems to reflect 
Figure 1 International Comparison in Commercial Energy Consumption and Carbon Dioxide Emission from Industrial Processes in 1995 (double-log scale)
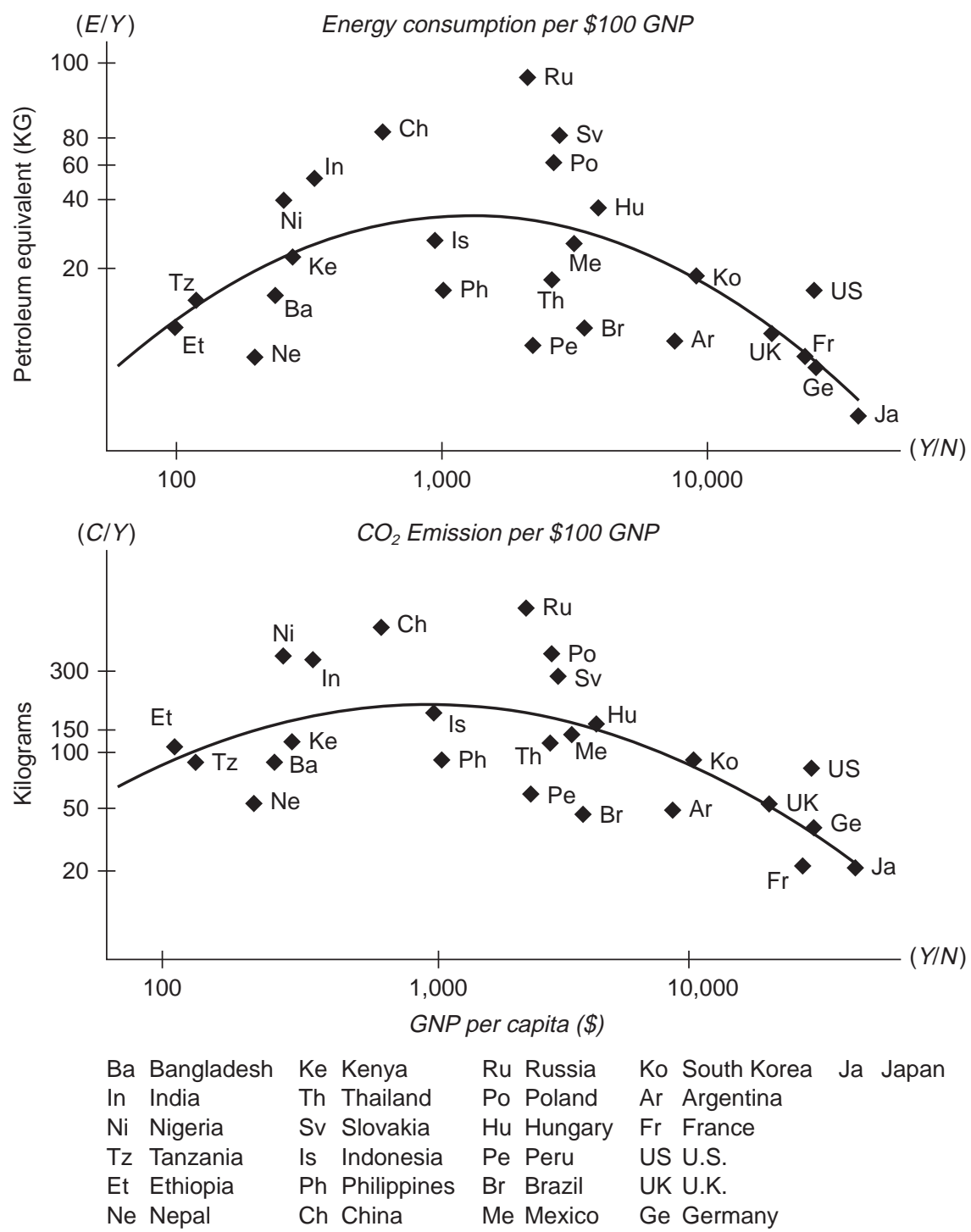

Note: Commercial energy excludes traditional energy from such sources as fuel woods. E/Y and $\mathrm{C} / \mathrm{Y}$ measured in 1995, and $\mathrm{Y} / \mathrm{N}$ in 1993-95 average.

Source: Based on data from World Bank, World Development Report, 1998/99, Selected World Development Indicators Table 1 and 10. 
the development strategy commonly adopted by the socialist states in accordance with the Soviet model. In this strategy, to assist industrial development, the cost of living for industrial workers and the prices of raw materials for industrial production were held low. Towards this end, the prices of foods and energy used to be set at very low levels. It is easy to imagine that these low prices induced abuse in energy consumption in both households and enterprises. Abnormally low efficiency in energy use was an unavoidable consequence when low incentives to save cost by managers of state enterprises, whose achievements were assessed solely in terms of output quantities relative to assigned targets (Hayami, 1997, pp. 217-220).

Another factor underlying abuse in energy consumption with little regard for environmental externality may be the nature of the socialist political system, which was not responsive to anti-pollution movements among citizens but rather inclined to suppress such movements. Under Western democracy, the government is at least officially supposed to mediate as a neutral third party between polluting firms and victimized citizens. Under the one-party autocracy of communism, polluting firms were a part of the government, against which citizens had difficulty in organizing opposition. They were also not equipped with such means as mass media and free voting rights to press the government. Under such a political regime, where industrialization was promoted with the compelling goal of achieving quantitative production targets, it was natural that state enterprises paid little attention to externality among surrounding dwellers. The experience in centrally planned economies clearly shows that state ownership (or 'people's ownership') of natural resources and capital in no way guarantees environmental conservation.

Regressions (3) and (6) assess the energy self-sufficiency rate as an explanatory variable. Coefficients of this variable turned out positive and significant, which correspond to upward divergence of energy-exporting countries (such as Indonesia, Mexico, and Nigeria) from the quadratic curves. Such results appear to reflect the tendency that in countries endowed with rich energy resources, energy prices are low, inducing high energy consumption. If this conjecture holds good, elevation of energy prices by such means as a carbon tax could promote savings in energy consumption, reducing emission of the polluting gas.

In all the regressions the inverted-U shape in the relationships of energy consumption and $\mathrm{CO}_{2}$ emission with per-capita GNP is statistically confirmed. The bottom row in Table 1 presents estimates of threshold-A, at which energy consumption and $\mathrm{CO}_{2}$ emission, both per 100 dollars of GNP, reach their peaks, range mostly within a range from $\$ 500$ to $\$ 1500$. As low-income economies begin industrialization and raise their per-capita income to this range, energy consumption and environmental pollution are likely to increase at rates much faster than growth in per-capita income. Once they pass this threshold, growth in energy consumption per-capita will become slower than per- capita income growth. This does not mean that environmental conditions will improve after this threshold point, because energy consumption will continue to increase abso- 
Table 1 Estimates of Regression Equations to Explain Commercial Energy Consumption and Carbon Dioxide Emission in 1995 from Industrial Processes per $\$ 100$ GNP based on Intercountry Cross-Section Data ${ }^{a}$

\begin{tabular}{|c|c|c|c|c|c|c|}
\hline \multirow[t]{2}{*}{ Explanatory variable } & \multicolumn{3}{|c|}{ Energy/GNP $\ln (E / Y)$} & \multicolumn{3}{|c|}{$\mathrm{CO}_{2} / G N P \ln (\mathrm{C} / Y)$} \\
\hline & (1) & (2) & (3) & (4) & $(5)$ & (6) \\
\hline GNP per capita: $\ln (Y / N)$ & $\begin{array}{l}2.093 * * * \\
(3.51)\end{array}$ & $\begin{array}{l}1.005^{* * *} \\
(2.23)\end{array}$ & $\begin{array}{l}0.765^{*} \\
(1.59)\end{array}$ & $\begin{array}{l}2.014 * * * \\
(2.97)\end{array}$ & $\begin{array}{l}0.911^{*} \\
(1.58)\end{array}$ & $\begin{array}{c}0.484 \\
(0.82)\end{array}$ \\
\hline $\ln (Y / N)^{2}$ & $\begin{array}{l}-0.145^{* * *} \\
(3.71)\end{array}$ & $\begin{array}{l}-0.074 * * \\
(2.49)\end{array}$ & $\begin{array}{l}-0.058^{* *} \\
(1.82)\end{array}$ & $\begin{array}{l}-0.147 * * * \\
(3.30)\end{array}$ & $\begin{array}{l}-0.074 * * \\
(1.96)\end{array}$ & $\begin{array}{c}-0.046 \\
(1.17)\end{array}$ \\
\hline Energy Self-sufficiency $\ln X$ & & & $\begin{array}{c}0.092 \\
(1.28)\end{array}$ & & & $\begin{array}{l}0.165^{* *} \\
(1.85)\end{array}$ \\
\hline Central planoning dummy $D$ & & $\begin{array}{l}1.151^{* *} \\
(5.27)\end{array}$ & $\begin{array}{l}1.164^{* *} \\
(5.41)\end{array}$ & & $\begin{array}{l}1.167^{* * *} \\
(4.17)\end{array}$ & $\begin{array}{l}1.190 * * \\
(4.49)\end{array}$ \\
\hline Intercept & $\begin{array}{c}-3.433 \\
(1.58)\end{array}$ & $\begin{array}{r}0.235 \\
(0.15)\end{array}$ & $\begin{array}{c}0.720 \\
(0.44)\end{array}$ & $\begin{array}{c}-1.693 \\
(0.68)\end{array}$ & $\begin{array}{l}2.025 \\
(0.98)\end{array}$ & $\begin{array}{c}2.890 \\
(1.43)\end{array}$ \\
\hline Coeff. of del. $\quad\left(R^{2}\right)$ & 0.377 & 0.719 & 0.728 & 0.415 & 0.665 & 0.700 \\
\hline S.E. of estimates $S E R$ & 0.577 & 0.388 & 0.382 & 0.656 & 0.497 & 0.470 \\
\hline \multicolumn{7}{|c|}{ Threshold value of $Y / N^{\mathrm{b}}(1993-95 \$)$ : } \\
\hline$A$ & 1,333 & 915 & 755 & 944 & 461 & 196 \\
\hline$B$ & 14,672 & 9,979 & 10,754 & 9,258 & 9,601 & 10,874 \\
\hline
\end{tabular}

Notes: ${ }^{a}$ Equations linear in logarithms are estimates by the ordinary least-square method based on data in Table 7.7. $t$-statics are shown in parentheses (absolute value). $E / Y, C / Y$ and $X$ measured in 1995 , and $Y / N$ in 1993-95 average.

b A: $Y / N$ which maximizes $E / Y$ or $C / Y$.

B: $Y / N$ which maximizes $E / N$ or $C / N$

*** Significant at the $1 \%$ level.

** Significant at the $5 \%$ level.

* Significant at the $10 \%$ level.

Sources: Based on data from World Bank, World Development Report, 1998/99, Selected World Development Indicators Table 1 and 10. 
lutely although at a decelerating pace. However, it is expected from the estimation of threshold-B that as per-capita GNP rises further to approach a level around $\$ 10,000$, both energy consumption and $\mathrm{CO}_{2}$ emission per capita will begin to fall absolutely. ${ }^{1}$

\section{Poverty and Environmental Degradation}

Though data are not available, it is likely that the rising phase of the environmental Kuznets curve for developing economies today is more steeply sloped than that experienced by developed economies in the past. First, it should be safe to assume that modern industrial technology being imported from developed economies today is much more intensive in the use of fossil fuel than that used by the latter when they were in an early development stage. Second, the first factor is often exacerbated by the policy of developing countries to promote heavy and chemical industries from the early stages of development. Third, growth of urban population in developing countries today, especially in their metropolitan cities, is incomparably larger than in the history of developed countries, implying much greater concentration of energy consumption and pollution. Fourth, developing economies entered the era of motorization before railway networks were established. Consequently, the density of automobiles is high relative to income levels, resulting in extreme city transportation congestion and serious air pollution.

In view of those negative effects, should policies be applied to curb industrialization and urbanization? Such policies might somewhat mitigate the urban pollution problem but they would be sure to invite a more serious problem. It must be recognized that a major factor underlying the 'pathological' growth of metropolitan cities in developing economies is the strong pressure of population growth on limited land resources that forces rural population to migrate into cities. A slow-down in the expansion of industrial and urban sectors inevitably results in increased population pressure in the rural sector.

As the supply of land suitable for cultivation becomes scarce relative to increased population under traditional agricultural technology, poor people are forced to cultivate fragile land for subsistence in hills and mountains, resulting in a high incidence of soil erosion. Also, they are forced to cut forests for timber and fuel as well as to overgraze animals on pasture lands to an extent exceeding the reproductive capacity of these natural resources. It is in such an environment that dire poverty or destitution typically becomes a vicious cycle. Poverty results in malnutrition and reduces poor people's capacity for work, precluding them from wage employment opportunities. They are thereby forced to rely more

1. These results are not inconsistent with a study based on data from the Global Monitoring System (a joint project of the World Health Organization and the UN Environmental Programme). Conspicuous pollution (such as sulphur dioxide density in the air) begins to decrease at an income threshold of about $\$ 4,000$ per person, and most other forms of pollution decrease from about $\$ 8,000$ (Grossman and Krueger, 1995). 
heavily on exploitation of fragile natural resources in marginal areas, to which property rights are not assigned (Dasgupta, 1993).

According to a global survey commissioned by the UN Environmental Programme, soil degradation during the five decades after 1945 amounted to about two billion hectares or about $17 \%$ of the total vegetative area in the world. As much as $80 \%$ of the degraded area was located in Africa, Asia and Latin America. About $30 \%$ of this degradation was caused by deforestation, $7 \%$ by overexploitation such as collection of fuels and fodder, 35\% by overgrazing, $28 \%$ from agricultural activities, and 1\% from industrialization (Oldeman et al., 1990). Clearly, a significant portion of the deforestation was caused by commercial logging. Degradation due to modern agricultural practices, such as an excess of irrigation water and chemical materials, cannot be overlooked. Yet, by far, the largest cause is identified as the exploitation of natural resources by rural people. Clearly, the poverty-induced depletion of natural resources is one of the major factors steepening the upward slope of the inverted-U-shape curve of environmental degradation, even though the aggregation of the effects of natural resource depletion caused by rural poverty with those of pollution caused by industrialization into a single curve has not yet been attempted.

To prevent such environmental destruction resulting from rural poverty, government regulations on the use of environmentally fragile areas may be necessary. However, the administrative capacity of government in developing economies is usually too weak to prevent a large number of desperate squatters from encroaching on wide remote areas of forest and grasslands. Moreover, if regulations were effectively strengthened, a means of subsistence for the poor would be closed. Short-term relief measures such as public distribution of food, water, and medical services might be necessary to rescue poor people from the trap of destitution. However, the fundamental solution to the problem should be directed to increasing employment and income by improving the productivity of the limited land already in use. This solution will not be possible without shifting from traditional resource-based to modern science-based agriculture, as symbolized by the so called 'Green Revolution' (Hayami and Ruttan, 1985, ch. 4).

There have been many criticisms of the Green Revolution for environmental reasons, e.g., directed against fertilizers and chemicals that poison soil and water causing ecological and human health damage. Also, it has been pointed out that irrigation without adequate drainage facilities tends to result in soil degradation through salinity and water logging. These effects are often serious. There is no question that major efforts must be allocated to overcome these problems through development of less poisonous chemicals, pest and insect control with reduced chemical application, and improved drainage facilities. ${ }^{2}$ However, if the efforts to develop modern technology were to be abandoned because of these defects, employment and income-earning opportunities for marginal farmers and agri-

2. For a comprehensive assessment of these influences on rice production in Asia, see Pingali, Hossain and Gerpacio (1997). 
cultural labourers would continue to be reduced under population pressure. As a result many would be forced to push cultivation frontiers into ecologically fragile lands, resulting in increased incidence of flood and soil erosion. Also, the development of agricultural technology should not be limited to favourable production environments with good irrigation conditions, but should be extended to both productivity increases and environmental conservation in fragile areas through such means as agroforestry and complementary use of arable lands and grasslands (Garrity, 1993).

\section{Lowering the Peak of the Environmental Kuznets Curve}

Under the relentless pressure of population growth upon limited land resources, however, the scope of poverty alleviation is bound to be inadequate if it is limited to the efforts to intensify agricultural production. It is hardly conceivable that the threshold of per-capita income, after which energy consumption and air/ water pollution per capita begin to fall absolutely (as illustrated by threshold-Bs in Table 1), can be reached without major progress in industrialization.

Can developing economies allow environmental degradation to continue worsening until such high income levels are reached? In both rural and urban areas the poor are the first to be endangered by environmental degradation. If this damage to poor people coincides with unequal income distribution, social and political stability, which is the basis of economic growth, will be seriously undermined. It is, therefore, critically important for developing economies to lower the peaks of the inverted-U-shape curves for both income distribution and environmental quality, while promoting industrial development.

Technically it is not so difficult to counteract environmental degradation. Ways and means for preventing environmental destruction in the rural sector have already been discussed. Pollution arising from industrialization and urbanization can be reduced in developing economies to a much lower level than that experienced by advanced economies in the past if technologies and know-how accumulated in the latter are effectively applied to the former.

It is also theoretically easy to design the institutions and policies to promote adoption of such anti-pollution technologies. The core of the environmental problem is the divergence between private and social costs in the use of the environment, which induces exploitation of environmental resources above socially optimum levels. Therefore, the environmental problem can be solved by raising the private cost of utilizing the environment (such as discharging noxious gas into the air) to the social cost.

Policy means to achieve this equality are well known theoretically (Tietenberg, 1990; Cairncross, 1992, ch. 5). Assignments of property rights are effective where the rights can be assigned and protected at modest cost (Coase, 1960). Property rights on environmental resources such as air and water can be set by allocating 'marketable pollution rights' or 'tradable permits' among firms and households on emission of polluting material. For example, permits may be 
allocated among chemical manufacturers to emit sulphur up to a certain quantity. If a manufacturer wants to emit more than his quota, he may do so by purchasing the necessary quota amount from another manufacturer. Through such transactions, equality in the marginal costs of abating sulphur emission will be established across firms, resulting in an increase in social utility from the initial quota allocation. If the total quota volume is determined at a level to equate the market price of the quota with the social marginal cost of sulphur emission, socially optimum pollution control can be established.

The same optimum control can be achieved with tax and subsidy according to the well-known theorem by Arthur Pigou (1920). For example, when a firm is producing negative externality from the production of a certain commodity, a tax on this commodity, equivalent to the externality, will raise the private marginal cost to the social marginal cost. Then, social optimum will be obtained at the intersection between market demand and market supply. The same optimum can be achieved by giving the polluting firm, for unit reduction in output, a subsidy equivalent to the difference between the private and the social marginal cost.

It has been statistically confirmed that efficiency in the use of energy is low in economies where energy prices are lowered by government subsidy below the international prices, while efficiency is high where energy prices are raised by taxation (Cairncross, 1992, pp. 77-80). This inefficiency can be reduced by the appropriate use of Pigovian tax and subsidy, resulting not only in reduction in environmental pollution but also growth in industrial production in the long run.

Nevertheless, efficient and feasible anti-pollution measures such as a carbon tax are not easily instituted even in high-income economies, for the very reason that they effectively raise energy prices and lower present incomes of energy consumers, who are apt to organize strong political opposition. This political barrier is even higher in low-income economies which are characterized by high preference for present over future consumption.

To overcome this barrier, the first requirement must be collection and dissemination of accurate information. Environmental degradation because of pollution tends to progress cumulatively and will reach devastating consequences in the long run. It is not easy in the early stage to accurately predict the dimensions of the final catastrophe, as illustrated by wide variations in predictions of the greenhouse effect of carbon dioxide. The more uncertain the future prospect is, the weaker is public opinion, and the less determined is government to undertake countermeasures.

However, it should be easier for developing economies to predict the course and consequences of pollution than it was originally for advanced economies. The reason is that, if developing economies promote industrialization without appropriate countermeasures, they are likely to repeat the past tragedies of advanced economies (e.g., mercury poisoning of humans through fish from chemical factory waste in Minamata, Japan). If such failures in advanced economies are accurately portrayed to leaders and the public in developing economies, it 
will become much more politically feasible to institute appropriate anti-pollution measures.

In this connection, it is critically important to organize the people in a community who are directly subjected to the effects of pollution. The people who can best monitor pollution are those living in the polluted area (e.g., residents who suffer from asthma due to a nearby factory spewing sulphur dioxide or fishermen whose catches decline because of polluted water). Traditionally, it has been the local communities, such as tribes and villages that have managed conservation of common property resources, such as forest, grazing land and fishing ground (Ostrom, 1990; Baland and Platteau, 1996). In modern societies also, if local communities are properly organized, they should be the most effective mechanism, not only for monitoring environmental conditions, but also for negotiating with polluters and lobbying government.

\section{From International Confrontation to Cooperation}

International cooperation, if designed properly, can do much to solve the apparent dilemma between conservation of the environment and the goal of economic development in developing economies. As mentioned in the introduction, international forums on environmental problems have been trapped in the stalemate of confrontation between developing and developed countries. In essence, developed countries have insisted that internationally uniform standards should be applied to environmental regulations on all nations, and that certain sanctions should be imposed, such as restrictions on import of commodities produced by violators of these regulations. On the other hand, developing countries have argued that it is unfair for developed economies that achieved development in the past by freely polluting the environment, to impose severe environmental regulations on developing economies as a yoke on their development. Therefore, they demanded that, if advanced economies requested them to adopt severe environmental regulations, their consequent economic losses must be made good by developed countries (World Bank, 1992; United Nations, 1993; Whalley, 1994).

Such controversy has ignored the possibility that international cooperation can be framed to benefit both parties. In terms of the classic framework of Pigou (1920), developed countries are demanding taxation of polluters based on the polluter-pay principle, whereas developing countries are considered to be arguing for subsidies to polluters based on the polluter-be-paid or the victim-pay principle. Because both can achieve optimality, as the Pigou theorem predicts, the issue is equity. If this controversy is raised as a domestic issue, the polluterpay principle seems to match the sense of equity and justice, since air polluters, for example, are mainly large enterprises and wealthy people whose energy consumption is high. However, it does not seem unjust for low-income economies to be compensated by high-income economies for the costs of reducing pollution. Rather, the former's demand for subsidies appears to be only fair, 
considering the fact, for example, that many low-income economies in the tropics are likely to be the chief sufferers from global warming even though high-income economies in the temperate zone are responsible for more than $90 \%$ of $\mathrm{CO}_{2}$ concentration in the atmosphere today (OECD, 1995).

Therefore, environmental conservation on a global scale should make significant progress if developed countries adopt the polluter-be-paid principle internationally vis-à-vis developing countries by advancing financial assistance and technical co-operation on the condition that developing countries establish relevant anti-pollution measures based on the polluter-pay principle domestically, such as the carbon tax. Considering the global externality of environmental destruction in developing economies, compensation payments to developing countries as a part of ODA for adoption of anti-pollution policies should prove to be a high pay-off investment opportunity for high-income economies in the long run.

In fact, an international application of the polluter-be-paid or victim-pay principle was already agreed at the Kyoto conference in 1997 with respect to reduction in the emission of greenhouse gases. This conference was the Third Conference of Parties (COP3) signed for the United Nations Framework Convention on Climate Change that was adopted in 1992 to prevent natural calamities, which might be caused by global warming resulting from increases in greenhouse gases such as $\mathrm{CO}_{2}$ and $\mathrm{CH}_{4}$.

The Kyoto conference concluded with an agreement that developed economies as a whole are obliged to reduce emission of greenhouse gases by more than $5 \%$ from the level of 1990 within the period from 2008 to 2012. ${ }^{3}$ No quota obligation was set on developing countries. Moreover, if a developed country undertook projects to reduce greenhouse gases in developing countries, the reduction could be counted as a contribution to filling its quota obligation. In the Pigovian framework this agreement is nothing but the application of the polluter-be-paid principle (though this word was not used in official documents), since it sets a rule by which the developed countries that suffer a part of pollution produced by developing countries pay for the cost of removing the pollution.

In addition to this Pigovian scheme of giving subsidies for the removal of pollution, the protocol of the Kyoto conference sets a rule by which a country unable to meet its reduction quota may purchase a part of other countries' quota in order to fulfil its own obligation. ${ }^{4}$ This scheme represents an international application of tradable emission permits along the Coase theorem, as explained before. With these rules it will become advantageous for developing countries to

3. The Kyoto Protocol to the United Nations Framework Convention on Climate Change (December 1997) stipulates the following quotas for the reduction gas emissions by country: $8 \%$ for EU, $7 \%$ for USA, $6 \%$ for Canada and Japan, and 0 for Russia and New Zealand. The protocol allows emission increases of $1 \%$ for Norway, $8 \%$ for Australia and $10 \%$ for Ireland.

4. The Kyoto Protocol remains as an agreement on the principles of the policies to be adopted. Concrete rules for their empirical application are supposed to be discussed in the subsequent conferences of parties for the final stipulation at COP6 in the fall of 2000. 
accept a certain quota on gas emission in exchange for an enlarged quota for developed countries. As it would become more difficult for developed countries to meet the increased quota, within their own territories, they would invest more heavily in the reduction of greenhouse gases in developing countries by such means as building purification facilities in factories and reforestation to absorb gases from the air. To the extent that the reduction may exceed the quota obligation by such investment in developing countries, the slack will be purchased by developed countries. The investment and income flows to developing countries will increase progressively as developed countries' quotas are enlarged and this could well exceed the disadvantage that developing countries may incur from the acceptance of certain emission quota. In this way, the participation of developing countries in the agreement on anti-pollution regulation need not be at the cost of their economic development.

Thus, it is perfectly possible to design international collaboration schemes that can achieve the dual goals of conserving the global environment and promoting the growth of developing economies, not only in relation to air pollution control but also for a variety of other problems. Such schemes can only be structured if institutions enlist the egoism of both developed and developing countries to act to achieve social optima at the global scale, rather than try to suppress this egoism.

\section{References}

Baland, J. M. and J. P. Platteau, 1996, Halting Degradation of Natural Resources: Is there a role for Rural Communities? Oxford University Press, Oxford.

Cairncross, F., 1992, Costing the Earth. Business Books, London.

Coase, R. H., 1960, The problem of social cost. Journal of Law and Economics, 3 (October), pp. $1-44$.

Dasgupta, P., 1993. An Inquiry into Well-being and Destitution. Clarendon Press, Oxford.

Dasgupta, P. and K. G. Maler, 1995, Poverty, institutions, and the environmental resource base. In J. Behrman and T. N. Srinivasan, Eds., Handbook of Development Economics, vol. 3A. Elsevier, Amsterdam, pp. 2371-2463.

Garrity, D., 1993, Sustainable land-use systems for sloping uplands in Southeast Asia. In Technologies for Sustainable Agriculture in the Tropics, ASA Special Publication No. 56. Crops Science Society of America and Soil Science Society of America, Madison, pp. 41-65.

Grossman, G. M. and A. Krueger, 1995, Economic growth and the environment. Quarterly Journal of Economics, 110 (May), pp. 353-377.

Hashimoto, M., 1994, Development and environment problem. Asian Economic Journal, 8 (Mar), pp. $115-145$.

Hayami, Y., 1997, Development Economics: from the Poverty to the Wealth of Nations. Oxford University Press, Oxford.

Hayami, Y. and V. W. Ruttan, 1985, Agricultural Development: An International Perspective, revised edn. Johns Hopkins University Press, Baltimore.

Kuznets, S., 1955, Economic growth and income inequality. American Economic Review, 45 (Mar), pp. $1-28$.

Oldeman, L. R., V. W. P. van Engelen and J. H. M. Pulles, 1990, The extent of human-induced soil degradation. In L. R. Oldeman, R. T. A. Hakkeling and W. G. Sombroek, Eds., World Map of the 
Status of Human-Induced Soil Degradation: An Explanatory Note. UNEP, and Wageningen: International Soil Reference and Information Center, Nairobi.

Organization for Economic Cooperation and Development (OECD), 1995, Global Warming: Economic Dimensions and Policy Responses. OECD, Paris.

Ostrom, E., 1990, Governing the Commons. Cambridge University Press, New York.

Pigou, A. C., 1920, The Economics of Welfare. Macmillan, London.

Pingali, P. L., M. Hossain and R. V. Gerpacio, 1997, Asian Rice Bowls: The Returning Crisis. CAB International, New York.

Selden, T. M. and D. Song, 1994, Environmental quality and development: is there a Kuznets Curve for air pollution emissions? Journal of Environmental Economics and Management, 27 (Sept), pp. 147-162.

Tietenburg, T. H., 1990, Economic instruments for environmental regulation. Oxford Review of Economic Policy, 6 (Spring), pp. 17-33.

United Nations, 1993, Agenda 21: Program of Action for Sustainable Development. UN, New York.

Whalley, J. W., 1994, Compensation or Retaliation: Developed and Developing Countries and the Growing Conflict over Global Environmental Conservation. IPR Discussion Paper 93. Institute for Policy Reform, Washington, DC.

World Bank, 1992, World Development Report 1992. Oxford University Press, New York.

World Bank, 1999, World Development Report 1998/99. Oxford University Press, New York. 